\title{
Large Volume Metrology Instrument Selection and Measurability Analysis
}

\author{
J E Muelaner, B Cai, P G Maropoulos \\ Department of Mechanical Engineering, The University of Bath, Bath, UK
}

\begin{abstract}
A wide range of metrology processes are involved in the manufacture of large products. In addition to the traditional tool setting and product verification operations increasingly flexible metrology enabled automation is also being used. Faced with many possible measurement problems and a very large number of metrology instruments, employing diverse technologies, the selection of the appropriate instrument for a given task can be highly complex. Also, since metrology has become a key manufacturing process it should be considered in the early stages of design, and there is currently very little research to support this. This paper provides an overview of the important selection criteria for typical measurement processes and presents some novel selection strategies. Metrics which can be used to assess measurability are also discussed. A prototype instrument selection and measurability analysis application is also presented with discussion of how this can be used as the basis for development of a more sophisticated measurement planning tool.
\end{abstract}

\section{INTRODUCTION}

Metrology is rapidly becoming central throughout the manufacturing process. The use of metrology begins with the setting of tools and continues through in-process measurement, metrology enabled automation, product verification and through life monitoring. Metrology should be considered a key manufacturing process and as such consideration of the measurability of product designs should be carried out early in the design stages.

The importance of design for manufacture has been well established [1-3] and design for measurability is an important aspect of this. Additionally process modelling has been shown to contribute significantly to process planning in areas such as tooling technology, welding and in particular at the early stages of design [3,4]. Despite the potential value of such a structured consideration of measurement operations there has been little work to integrate metrology process models with design evaluation and assembly planning.

Previous work [5] has laid out a generic framework for measurement planning. The work in this paper details the rational behind an initial instrument selection software application. This prototype software will serve as the basis for further development of more sophisticated measurement planning tools and there is also some discussion of how this might take place.

Diverse measurement tasks require a range of different instruments and there are many competing technologies, each offering specific advantages and disadvantages for certain applications. Faced with a wide range of different measurement technologies the decision of how best to measure a product becomes complex as does the assessment of the measurability of a new design.

There are essentially two different tasks which require the support of process modelling techniques. Firstly the role of the designer in assessing the measurability of a product in the early stages of design and secondly the process planner determining the optimum process to carry out measurements related to some production process. In reality these tasks require the same steps to be taken. In either case the purpose of measurement must first be specified, preferably in terms of a set of unambiguous and quantifiable criteria. Different measurement systems can then be assessed to determine their suitability and some selection then made.

In the case of the designer the emphasis would be on optimizing the design of the product to improve measurability. In the case of the process planner the emphasis would be on optimizing the measurement process to fully meet the criteria. In either case an entirely quantitative assessment can only be made if the performance characteristics of the proposed measurement process can be related to the measurement process specification in such a way that a capability index is generated [5].

A simpler approach is to relate each measurement instrument's performance to the measurement process specification in order to generate a simple pass or fail condition. This approach has some benefit in that it is likely to be simpler to implement and would allow the user to apply some judgement to assessing a reduced subset of possible processes.

This approach of assessing possible measurement processes in terms of pass or fail with respect to a 
measurement process specification serves as the basis for the creation of the software described in this paper. A database filter can be used to include instruments that meet a defined specification. It is also shown that this approach can be easily extended to include a measurability index.

The operation of this software has three stages; specifying the measurement process requirements, modelling measurement processes and assessing the suitability of the processes for carrying out the measurement. These are discussed in turn.

\section{SPECIFYING THE MEASUREMENT PROCESS REQUIREMENTS}

There are many possible reasons for employing a metrology system. The most obvious is product verification or tool setting but measurements may also be used to track parts into assembly positions or to guide automation systems. In order to facilitate the structured assessment of measurement processes it is first important to clearly specify the requirements for the measurement. Regardless of the application the same generic specification variables can be used to define the measurement process such as:-

- The dimensions of the measurements

- Physical access and visibility

- The tolerance to be verified or the level of uncertainty required

- The number of individual measurements required and the time available to take the measurements

- The environmental conditions under which the measurements are to take place

- The interface with the part; contact, non-contact, fixed targets etc.

- The degrees of freedom; distance, position, orientation.

- Portability of the instrument

- Cost

- Technology Readiness Level

The significance of these specification variables will now be considered in turn.

\subsection{Dimensions of the Measurement}

Instruments have a finite range and field of view and are therefore limited in terms of the size of object they are able to measure. The size of the object will also have an effect on the uncertainty of measurements as discussed in section 2.3.

A comprehensive specification of the process requirements would be best represented using a threedimensional solid model. For practical purposes a simple statement of the maximum distance between measurement points on the part and the maximum range from the instrument can be used. Typically it would be assumed that the maximum range will be equal to the maximum distance between measurement points.

\subsection{Physical Access and Visibility}

The shape and position of the part which is to be measured will determine whether measurement with a given system is a possibility due to considerations of access. With traditional mechanical measurement devices such as micrometers and height gauges physical access to the part is a clear necessity. With optical instruments the requirement becomes for unobstructed line-of-sight along which rays of light may propagate.

Information transfer is a more generic way to describe this. For example in the case of the traditional instruments we could say that the transfer of information from the measured point to the instrument datum or from one measurement to the next takes place through mechanical linkages. Alternatively the transfer may take place through single or multiple lines-of-sight. In either the physical access or the line-of-sight example the information can only realistically propagate through a fluid (the air) or vacuum. There are however many other less common possibilities such as magnetic flux, x-rays, ultrasound etc which are able to propagate though solids.

Regardless of whether an algorithm is created to check for access and visibility automatically or whether manual checking is to be carried out the measurement process requirements should be specified using a threedimensional solid model of the part and any surrounding tooling.

\subsection{Measurement Uncertainty and Part Tolerances}

Accuracy is clearly important in metrology and is generally inversely proportional to the scale of the measurements being taken. Accuracy is also dependent on the operating environment as described in the ASME standard relating to Laser-Based Spherical Coordinate Measurement Systems [6]. In order to ensure an unambiguous definition accuracy should more properly be defined as measurement uncertainty [7].

Measurement uncertainty is a key performance indicator for any measurement instrument. The level of uncertainty will determine whether it can be proven that a part conforms to specifications. Additionally the uncertainty of measurements will affect the cost of forming operations and product rejection rates.

If the tolerance for a part gives a minimum and a maximum value then when the part is measured using a given instrument, allowance must be made for that instrument's uncertainty. The uncertainty of the measurement is added to the minimum value to give a minimum acceptance value. Similarly the uncertainty is subtracted from the maximum value to give a maximum acceptance value. When the part is measured the reading must be within the range of the acceptance values in order to say that the part is within the tolerance. This range of acceptance values, or residue tolerance, is the tolerance required by the manufacturing process. 
We can say that there are five possible scenarios when making a measurement as illustrated graphically in Figure 1.

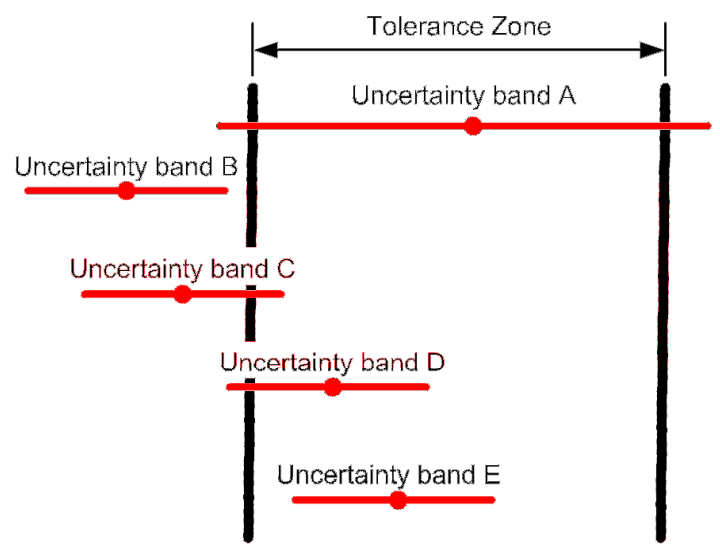

Figure 1 - Possible Interactions between Tolerance Zone and Uncertainty Band [8]

A. The uncertainty of the instrument is greater than the tolerance of the part and so it will never be possible to determine whether the part is within tolerance.

B. The uncertainty of the instrument is less than the tolerance of the part. The reading shows the part to be sufficiently out of tolerance that there is no overlap between the tolerance zone and the uncertainty band. We can therefore state with confidence that the part is out of tolerance. This is the only case where a customer can legitimately reject a part [9].

C. The uncertainty of the instrument is less than the tolerance of the part. The reading shows the part to be out of tolerance but there is overlap between the tolerance zone and the uncertainty band. The part may be in tolerance but must be rejected.

D. The uncertainty of the instrument is less than the tolerance of the part. The reading shows the part to be in tolerance but there is overlap between the tolerance zone and the uncertainty band. The part is probably in tolerance but we can not state this with confidence and therefore it must be rejected.

E. The uncertainty of the instrument is less than the tolerance of the part. The reading shows the part to be sufficiently within the tolerance that there is no overlap between the tolerance zone and the uncertainty band. We can therefore state with confidence that the part is in tolerance. This is the only case where a supplier can prove conformance [9].

The measurement process requirements should be specified in terms of the tolerance which must be achieved. For product verification applications the conformance conditions discussed above will be directly relevant. For metrology enabled automation the relationship between the process capability and the uncertainty of the guiding metrology system will be related in a similar way.

\subsection{The number of measurements required and time available}

Some measurements will be for a single length, typically measured by locating two points. The characterization of a surface on the other hand will involve the measurement of a large number of discrete points.

The performance specifications of instruments, published by manufacturers, often state the measurement frequency. This is misleading since most instruments are capable of relatively high frequencies but a single measurement has a low accuracy. Generally averages of a number of measurements are used to reduce the effects of environmental disturbances such as vibration and turbulence. Closely related to frequency is concurrency; whether the instrument measures multiple points sequentially or concurrently. Many instruments will measure each point in sequence but multi-sensor networks may be able to measure points at multiple sensors concurrently and those based on photographic techniques will be able to image a large number of points concurrently, limited by pixel count and target size.

In specifying the measurement process requirements we must state the number of individual measurements required and the total time available to make these measurements.

\subsection{Environmental Conditions of Measurement}

Specification of the environmental conditions in which the measurement is to be carried out should include the average temperature, temperature gradients, pressure, humidity and carbon dioxide content.

\subsection{Interface with Part}

Metrology instruments are often grouped into contact and non-contact devices. The statement that an instrument is non-contact should not be confused with the totally different performance characteristic of being frameless. No part of a non-contact instrument makes physical contact with the artefact being measured; typically light scattered from the object is used to make the measurement. Contact instruments on the other hand include conventional instruments such as micrometers which must physically located against measurement features.

A laser tracker $[10,11]$ is a good example of an instrument where confusion may arise. Although the main body of the laser tracker does not make contact with the part a retro-reflective target does physically touch the part. Since there is no mechanical connection between the retro-reflector and the laser tracker this instrument is considered frameless, however, since the retro-reflector touches the part it can not be considered a non-contact device. 
Due to physical access or health and safety constraints it may be necessary to specify that non-contact measurements should be made. It is likely that noncontact measurements will also be faster as on operator is not required to position targets. The measurement process should however not be constrained to non-contact measurement on the basis of speed since proper modelling of the measurement time is the correct way to make unbiased decisions based on process time. The modelling of measurement time is covered in section 3.3.

\subsection{Degrees of Freedom}

It is important to consider how many degrees of freedom (DOF) are required. For example, is the simple onedimensional distance between two hole centres sufficient or is there a requirement for the three-dimensional coordinates of each point?

Informational richness is a term that could be used to encompass the degrees of freedom in addition to other information. For example, traditional instruments are usually one-dimensional (1 DOF), a micrometer or callipers are able to measure a single length, the next level of informational richness is two-dimensional (2 DOF) part detection, these are devices able to detect a sensor or locate a probe on a surface. The next level of informational richness is two-dimensional shape recognition, able to measure holes and other features on sheet parts. This demonstrates that there are levels of information which can not be fully described by the DOF alone.

Three-dimensional (3 DOF) point measurement is the measurement of discrete positions in space. These systems generally use some form of probe possibly in the form of an optical target and are actually measuring the center of this probe.

Six degree of freedom (6 DOF) systems are able to measure both the coordinates and the rotation of a sensor or target; these systems are particularly useful for providing feedback to automation.

Finally 3D surface characterization is able to detect the complete form of an object and digitize this, essentially a CAD model can be created from a physical artefact. Generally these systems will require line of sight so a number of observation points will be required to digitize a complete object.

In actual fact 2D part detection and 3D surface characterization abilities are the combined effect of the degrees of freedom (2D or 3D) and the point acquisition rate. Informational richness can therefore be represented by the degrees of freedom together with the number of individual point measurements required to adequately characterize a feature. The DOF's required for a given measurement process should be stated as a minimum; if three-dimensional coordinates are required then a 6 DOF instrument would also be suitable but a 1 DOF instrument would not.
The definition described above assumes that a 1 DOF instrument is able to measure a length and a 2 DOF instrument measures coordinates on a surface. In reality there are common instruments such as theodolites which are also 2 DOF but which measure two angles locating a target at some point on a line. This simplified definition is used to facilitate data sorting and filtering and the limitation must be noted. It is anticipated that more sophisticated algorithms will be adopted in future to address this deficiency.

\subsection{Portability of the Instrument}

In some cases it may be necessary to specify whether an instrument can be easily transported and rapidly set-up on site. In such a case the specification can be simply stated as a maximum packed volume and a maximum set-up time.

\subsection{Cost}

There are various ways to consider measurement cost, as described in section 3.8. There may be a constraint on the capital cost of the instrument or on the total process cost per unit. Alternatively the requirement may simply be to find the cheapest process that will meet some other minimum criteria.

\subsection{Technology Readiness}

The consideration of Technology Readiness Level (TRL) is important since the maturity of the metrology instrumentation must be suited to the application. For example a production application will require a fully mature commercial product, preferably with qualification to international standards. For a research application on the other hand a prototype cutting edge system may be more appropriate.

Common definitions for TRL's are published by the Department of Defence [12] and the National Aeronautics and Space Administration [13]. Based on these a simplified four level TRL scheme for large volume metrology technologies is proposed as detailed in Table 1.

Table 1 : Technology Readiness Levels (TRL's) in Large Volume Metrology

\begin{tabular}{|c|c|}
\hline Level & Description \\
\hline TRL 1 & $\begin{array}{l}\text { Basic measurement principles observed } \\
\text { and reported }\end{array}$ \\
\hline TRL 2 & $\begin{array}{c}\text { Measurement system, subsystem model } \\
\text { or prototype demonstration }\end{array}$ \\
\hline TRL 3 & $\begin{array}{c}\text { Actual system completed and sold in the } \\
\text { commercial market }\end{array}$ \\
\hline TRL 4 & $\begin{array}{c}\text { Actual system qualified by international } \\
\text { standard }\end{array}$ \\
\hline
\end{tabular}




\section{MODELLING MEASUREMENT PROCESSES}

An assessment of the capability of a measurement system to meet the process specification is required. In order to do this it is necessary to model the performance of the measurement system with regard to the operating conditions defined within the measurement process specification. Process models have been created to achieve this. Such process modelling work first requires that metrology instruments and processes are classified into generic types which can be understood using common models.

Various classifications of metrology instruments are possible such as flat hierarchic structures [14-16]. The classification of metrology instruments is complex and a simple flat hierarchy cannot fully characterize a group of instruments. Furthermore many instruments can operate in more than one mode and therefore fit into multiple categories for a particular property making such a classification potentially misleading. An interesting Venn diagram of the fundamental technologies used by different area scanning instruments with some illustration of the relative advantages is presented by Mermelstein [17]. Although this approach is informative it also does not fully capture all the possible considerations that may be important in selecting an instrument for a given task.

The most important initial level of classification, with respect to modelling instrument performance, is between distributed systems and centralized systems. Distributed systems combine measurements from multiple instruments and therefore any model of a distributed system first requires an understanding of the component instruments.

A complete classification of individual instruments has not been attempted in this work but some generic instrument types which are of particular interest have been identified and are discussed in relation to specific properties. Some generic models for distributed networks are also discussed. The rational for the partial classification presented can serve as the basis for more rigorous classification in future work.

\subsection{Modelling Access and Visibility}

The software application presented in this paper does not allow the automatic checking of physical access and lineof-sight visibility. Checks can be carried out relatively easily using three dimensional computer aided design (3D CAD) software. A model of the measurement instrument, complete with extruded cylinders to represent any linesof-sight, can be assembled with the product and checks for measurability thus carried out using a similar process to that normally applied to checks for assembly accessibility. It can be envisaged that a more sophisticated measurement planning tool might include such facilities. In fact the Spatial Analyzer [18] product does include some of these features, to a limited extent, despite lacking many of the other features discussed in this work.
It is also possible to envisage a 3D digital environment which is able to place constraints on the positions of instruments so that lines of sight are maintained. It would then be possible to optimize the positions of instruments within these constraints to achieve other favourable performance characteristics such as minimization of uncertainty.

If a more generic information transfer property is considered allowing the inclusion of magnetic flux, x-ray and ultrasound based devices then some qualitative description and consideration is likely to be required with the possibility for automatic checking less likely.

Detailed models of the access and visibility constraints involved in carrying out a measurement with a given instrument may be created in future work. Before this is carried out it will be necessary to create an instrument classification which is appropriate for these models.

\subsection{Modelling Uncertainty}

Process models are required which describe the uncertainty of different metrology systems as a function of the measurement process specification variables. Much work has already been carried out in this area [19]. The uncertainties associated with optical disturbances due to environmental factors are described by models created for laser-lased spherical coordinate measurement systems, such as laser trackers and laser radar [6]. These models can be applied to any optical instrument if the refractive index is calculated for the environmental conditions and the wavelength of light used by the instrument [20,21].

A simple process model for the range dependent uncertainty of laser-based spherical coordinate measurement systems is described in the ASME standard for these instruments [6], this is summarized below.

$U_{r}=A+B \cdot r$

$U_{a}=C+D \cdot r$

Equation ( 1 ) gives the uncertainty for measurements in the radial direction from the laser tracker where $r$ is the radial distance at which the measurement is taken. Equation ( 2 ) gives the uncertainty for measurements in the tangential direction. $A, B, C$ and $D$ are constants which characterize the uncertainty of a given laser tracker.

Pin-hole camera models [22], which are a well established method of modelling the uncertainty of the individual cameras used in photogrammetry systems, are unnecessarily complex for the purposes of this work. A simple model for individual cameras using equations of the form of equation ( 2 ) would be more appropriate. This simplified approach to specifying uncertainty as a function of range is used by manufacturers [23].

Coordinate measurements may be calculated from a number of angular measurements obtained using cameras, theodolites, iGPS [24] etc. The uncertainty of 
measurements made by such a network can be determined using bundle adjustment algorithms [25]. Similar techniques have also been used to estimate the uncertainty of coordinate measurements made by combining measurements of range; a technique known as multilateration [26].

The Monte Carlo method also provides a general technique which can be used to propagate the uncertainties of multiple instruments through to coordinate measurements made by the network as a whole [27]. This technique is useful as it can readily be applied to virtually any instrument model, although it is somewhat computationally intensive.

From a design for measurability perspective feedback to the designer should be in the form of a residue tolerance, as discussed in section 2.3. It is this residue tolerance which will affect the cost of the other processes used to form the part.

\subsection{Modelling Measurement Time}

The process specification will state the number of individual measurements required. It is then necessary to calculate the total time which each metrology system will require to carry out this task. This may be stated as the composite time $\left(T_{P}\right)$ required to take a number of measurements using a given system. In order to define this performance characteristic as a function of the measurement process specification it is necessary to define a number of variables.

The actual number of points which can potentially be measured concurrently $\left(N_{a}\right)$ must be specified as part of the measurement process specification. The other variables are all performance characteristics of the instrument configuration. Examples of $N_{a}$ include the number of points to be measured on a part before it is moved to a different position or the number of points to be measured from one view point before the instrument is moved to a different position. The number of points the instrument is able to measure concurrently is denoted by $N_{I}$.

The typical time required to take a single measurement $\left(t_{m}\right)$ is generally not simply the reciprocal of the measurement frequency but rather includes the whole measurement process; positioning the target and taking repeated measurements for averaging etc. For example, a Laser Tracker requires time for the instrument to actually measure and for the operator to move the SMR to the next nest, for sequential multi-lateration this time is multiplied by the number of station positions. For a Laser Scanner $t_{m}$ will simply be the reciprocal of the instruments' measurement frequency.

The positioning time $\left(t_{P}\right)$ is the setup time required each time either the part or the instrument is moved. For example when using sequential multi-lateration, where the part is measured using a single instrument from multiple view point stations, this will be the total time for all the station moves.
Equation ( 3 ) defines the composite time $\left(T_{P}\right)$ in terms of the variables defined above. It is important to note that this is an approximation making the assumption that $N_{a}$ is a multiple of $N_{I}$ for the case where $N_{a}>N_{I}$. It never-theless provides a useful way to compare instruments as has been demonstrated through case study based use of the prototype system.

$$
\begin{aligned}
& \text { if } \quad N_{a} \leq N_{I} \\
& T_{P}=t_{m}+t_{P} \\
& \text { if } \quad N_{a}>N_{I} \\
& T_{P}=\frac{t_{m} \cdot N_{a}}{N_{I}}+t_{P}
\end{aligned}
$$

This process model is entirely generic and does not require any process classification.

Although it is the composite time rather than the measurement frequency that is of importance when determining the speed with which a given instrument is able to complete a given measurement task this is not the case when considering environmental disturbances. In order to reduce the effects of vibrations and turbulence a large number of measurements are normally taken and the results averaged. The frequency of the instrument should be compared with the expected frequency of environmental disturbances and some consideration of the appropriateness made. For example if the two frequencies are the same then there will be no improvement in accuracy from averaging a number of measurements. For this reason it may be beneficial to randomly vary the measurement frequency.

\subsection{Environmental Conditions for Operation of Instruments}

There are two aspects to consider concerning the environmental conditions. Firstly, is the instrument able to function within the operating environment, and secondly, what effect will the environmental conditions have on the performance of the instrument? In particular, how will temperature gradients affect the measurement uncertainty?

Process models which describe the uncertainties associated with optical disturbances due to environmental factors are covered in section 3.2.

The operational limits for instruments should be specified as simple maximum and minimum conditions for properties such as temperature, pressure and humidity. The decision as to whether the instrument specification is within the operating conditions should then be based on the average temperature specified, the product of the temperature gradient and the maximum range, and an additional safety margin should also be added.

\subsection{Interface with Part}

Whether a particular instrument makes contact with the part can be described as a simple Yes/No condition. 


\subsection{Degrees of Freedom}

Provided that the assumption made in section 2.7, that a 1 DOF instrument measures length etc, then the degrees of freedom of an instrument can be given a simple numerical value. This will allow a straightforward filtering for instruments with at least the required degrees of freedom.

\subsection{Portability of the Instrument}

Two performance characteristics can be used to describe the portability of an instrument; the packed volume and the set-up time.

\subsection{Modelling Measurement Cost}

Modelling the cost associated with measurement operations is a highly complex subject and one with no clear conclusion at this stage. The problem is that uncertainty in measurement has implications for part rejection rates and the accuracy of other manufacturing processes, which in turn have associated costs. It is therefore very difficult to access the true cost of choosing one process over another.

The simplest approach is to ignore the impact which measurement uncertainty has on part rejection and other process requirements entirely. The cost of the measurement can then be considered to derive from the capital costs of the measurement equipment, the utilization rate of the equipment and the labour costs of carrying out the measurement as described by Cai [5] and summarized below. The total measurement cost which is directly attributable to the measurement activity $\left(C_{c}\right)$ is then given by

$$
C_{c}=C_{U}+C_{d}+C_{O}
$$

where $C_{U}$ is the utilization cost, $C_{d}$ is the deployment cost and $C_{O}$ is the operating cost.

The utilization cost is related to the depreciation cost of the instrumentation, based on the activity depreciation method [28], and is given by

$$
C_{U}=\frac{T_{m}}{T_{l}} V_{s}
$$

where $T_{m}$ is the time for which the instrumentation is occupied by the operation, $T_{l}$ is the expected life of the instrument and $V_{s}$ is the total value of the instrumentation.

The deployment cost is the labour related cost of instrument set-up given by

$$
C_{d}=C R_{d} \cdot T_{d}
$$

where $C R_{d}$ is the cost per unit time for labour related deployment costs and $T_{d}$ is the estimated deployment time for the selected measurement system.

The operating cost is the labour related cost of operating the instrument given by

$$
C_{o}=C R_{o} \cdot T_{o}
$$

where $C R_{o}$ is the cost per unit time for labour related operating costs and $T_{o}$ is the time required to carry out measurement.

The simplified cost model described above ignores the affect of measurement uncertainty on part rejection rates and on the accuracy requirements for other processes.

The cost of part rejection due to measurement uncertainty can be calculated given the following variables which are illustrated in Figure 2:-

The cost of the component

The component tolerance being measured

The measurement uncertainty

The manufacturing uncertainty (does the required tolerance represent $+/-2$ or 3 sigma)

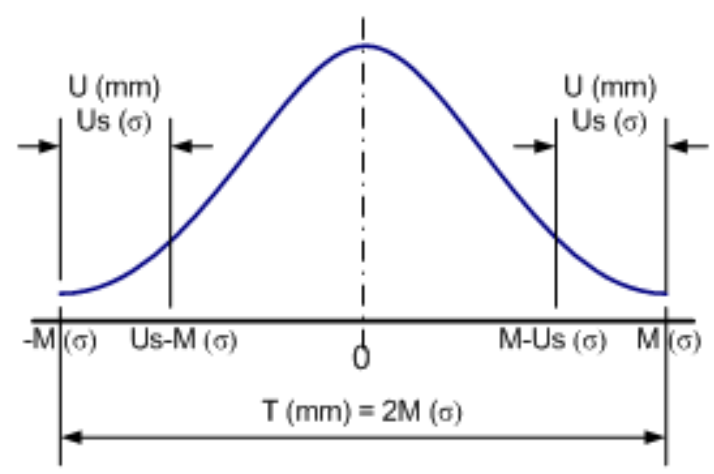

Figure 2 : Part Rejection due to Measurement Uncertainty

The component tolerance and the measurement uncertainty both have units of length. The measurement uncertainty can be converted into standard deviations of the part by:-

$U s=\frac{U}{T} 2 M$

We can then say that the percentage of parts, which are within tolerance, and that are rejected due to measurement uncertainty $(\mathrm{R})$ is given by equation ( 9 ) which uses Microsoft Excel syntax.

$\mathrm{R}=2^{*}$ (NORMSDIST (M+Us)-NORMSDIST(M))

The cost of this rejection is then simply $\mathrm{R} * \mathrm{C}$ per part. This model assumes that a strict conformance condition is applied [9] and that the process is under statistical control.

In order to achieve a reasonable rejection rate with a given level of measurement uncertainty it may be necessary to improve the accuracy of the manufacturing process. This will also have an associated cost which will be highly dependent of the manufacturing processes used. The consideration of these costs would require a holistic 
approach to process planning which is beyond the scope of this paper.

\section{INSTRUMENT SELECTION AND MEASURABILITY ANALYSIS}

Instrument selection, measurability analysis and measurement process planning should be carried out numerous times as a product progresses from concept though to the design of the manufacturing process. This is required since the initial assessment of the measurability of concept designs will necessarily be carried out using incomplete information. For example the lines of sight available to measure a product will depend on the exact design of jigs and tooling which will not be decided until relatively late in the design of the production process.

A number of possible strategies for instrument selection and measurability analysis have been identified and these are discussed below.

\subsection{Instrument Selection by Data Filtering}

A pragmatic approach which has already been applied to the selection of instruments for industrial processes involves a database containing two tables. The first table is used to specify certain aspects of the measurement process requirements and the second to store the performance characteristics of the instrument configurations. The performance characteristics in the second table may be dynamically generated as functions of the variables in the first table. The remaining aspects of the measurement process specification not specified in the first table are then stated as database queries, such as filters and sorts, applied to the second table.

This approach allows the efficient selection of instruments and multiple instrument networks with minimal development costs. A similar approach, described by Cuypers [29], involves specifying the task requirements, environment restrictions and part restrictions before selecting instruments manually. The creation of databases and the use of data filtering to aid selection is a logical progression of these ideas.

The measurement process definition table details the range and distance between points to be measured, the number of points on the part and the temperature gradients present in the working volume.

The instrument specification table has three classes; instrument type, instrument and configuration. Each instrument type can have multiple instruments and each instrument can have multiple configurations. Each configuration has a number of performance characteristics such as measurement uncertainty and measurement time which may be defined as functions of the measurement process specification variables.

This database approach, detailed fully in the appendices, allows the measurement process requirements to be first specified and then for appropriate instruments to be selected using standard data filtering techniques.

\subsection{Index Based Assessment}

A straightforward extension of the data filtering and sorting application discussed above is the addition of capability index calculation. The capability indices can be added to the instrument specification table as performance characteristics defined, for each instrument configuration, as a function of the measurement process specification variables and/or other performance characteristics of the instrument configuration. When the operator is filtering and sorting to select instruments it then becomes possible to filter for instruments which have a particular range of values of a given capability index or to sort to find the instrument with the best value.

The use of capability indices also facilitates the use of automated data filtering. For example a traditional 'rule of thumb' has been that a measurement system should have an accuracy (or uncertainty in modern terms) ten times less than the tolerance of the dimension being measured. Due to significantly reduced tolerances this rule is often now relaxed to four times [30]. An automatic filter could remove all instruments which do not meet this condition. This measurement accuracy capability index [5] $\left(C_{m}\right)$ is defined as

$$
C_{m}=\frac{T}{U}
$$

where $T$ is the tolerance of the dimension being measured and $U$ is the expanded uncertainty of the measurement instrument.

This measurement accuracy capability index can be converted to a dimensionless comparative value. For the ith measurement system in a database which contains $n$ measurement systems, the dimensionless measurement accuracy capability index is given by

$$
C_{m_{i}}^{\prime}=C_{m_{i}} / \sum_{i=1}^{n} C_{m i}
$$

Similarly the measurement cost and the technology readiness level can be converted to dimensionless indices. The dimensionless cost index is given by

$C_{c_{i}}^{\prime}=C_{c_{i}} / \sum_{i=1}^{n} C_{c i}$

where $C_{c i}$ is the cost for the ith measurement system calculated using equation ( 4 ).

The dimensionless technology readiness index is given by

$C_{r_{i}}^{\prime}=C_{r_{i}} / \sum_{i=1}^{n} C_{r i}$

where the technology readiness index $C_{r}$ is simply equal to the integer value of the technology readiness level as given in Table 1.

The calculation of these dimensionless indices should be carried out after data filtering. This will ensure that the 
comparison is between only those instruments which are able to meet the basic requirements such as having access to the measurement and being able to operate within the specified environment.

Cai et al[5] have proposed that these dimensionless capability indices can be combined to give an overall measurement capability index using equation ( 14 ).

$I_{i}=w_{1} C_{m i}^{\prime}+w_{2} C_{c i}^{\prime}+w_{3} C_{r i}^{\prime}$

where $w_{1}, w_{2}$ and $w_{3}$ are weights corresponding to each individual capability index.

Considering equation ( 14$), C_{m}$ is the ratio of measurement uncertainty to the part tolerance and as such larger values are preferable, $C_{c}$ is an estimation of the cost of the measurements and so smaller values are preferable, and $C_{r}$ is a the technology readiness level with larger values preferred. Therefore $w_{1}$ and $w_{3}$ will take positive values while $w_{2}$ will take a negative value.

An alternative form for the combined capability index might be

$I_{i}=e^{w_{1}} C_{m i}^{\prime}-e^{w_{2}} C_{c i}^{\prime}+e^{w_{3}} C_{r i}^{\prime}$

Further work should investigate the optimum method of combining the capability indices. Feedback to the user may be a simple numerical readout or preferably a graduated Red - Amber - Green colouring could be used to vividly represent the suitability of each measurement system.

The inclusion of the measurement accuracy capability index, reflecting the measurement uncertainty, is largely required because the simplified cost term does not reflect the cost of measurement uncertainty. In a fully developed solution it may be possible to accurately model the full cost implications of measurement uncertainty. At that stage it may no longer be deemed necessary to include a separate term reflecting uncertainty or alternatively that term may assume a greatly reduced weighting.

\section{PROTOTYPE SOFTWARE}

The prototype software has been created using a database management system (DBMS) and consists of two tables; a measurement process specification table and an instrument performance table. These tables are detailed in the appendices. An overview of the flow of information within the prototype software application is given in Figure 3.

The measurement process specification table contains the user inputs which specify the process requirements and are used as variables by the instrument process models. This table has a single record and each field therefore occurs only once.

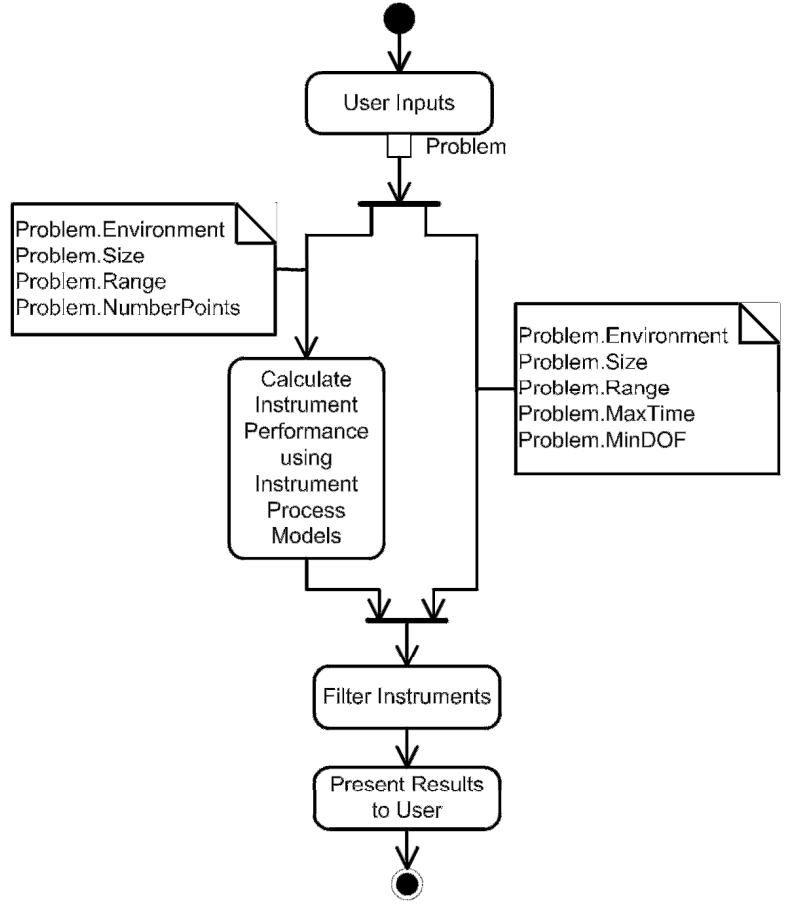

Figure 3: UML Activity Diagram of Instrument Selection and Measurability Analysis Software Function

In the instrument properties table there is a record for each instrument configuration. For example a laser tracker may be used as a one-dimensional range measurement device, as a centralized three-dimensional coordinate measurement machine or as a distributed network of, for example, four laser trackers forming a three-dimensional coordinate measurement machine etc. Each of these configurations has a separate record in the database. Many of the values in the instrument table are dynamically generated using variables stored in the measurement process specification table.

The process specification table does not contain all of the variables defining the measurement process requirements. Instead the process specification table contains only those variables which are used to generate the instrument performance characteristics stored in the instrument database. The final process specification variables used to filter and sort the data contained in the instrument table are input directly as filter and sort constraints using the database management system's default interface.

\subsection{An Industrial Case Study}

Work has been carried out to develop assembly processes within a major aerospace company. This work has identified a number of generic measurement tasks such as jig setting, surface characterization, metrology assisted robotic machining and metrology assisted datuming of precision machine tools. As an example of the use of the use of the prototype software a surface characterization process is specified below.

The generic surface characterization process would assume that:- 
- The instrument is located at a range equal to the size of the part being measured

- That measurements are carried out in a typical production environment (average temperature $20^{\circ} \mathrm{C}$, $1{ }^{\circ} \mathrm{C} / \mathrm{m}$ temperature gradients, $101 \mathrm{~K} \mathrm{~Pa}$ atmospheric pressure, $50 \%$ relative humidity and $450 \mathrm{ppm} \mathrm{CO}^{2}$ )

- That all measurements should be carried out within an hour.

- 3D coordinates are required.

In addition to these generic requirements given above the specific application, which will not be described in detail for commercial reasons requirements, involved the measurement of 80 points over an area of approximately 8 $\mathrm{m}$ by $2.5 \mathrm{~m}$ with an expanded uncertainty of less than $\pm 0.076 \mathrm{~mm}$. These constraints were entered into the instrument selection database which did not contain any instruments able to achieve this level of performance.

Alternative processes were then considered. For example it might be acceptable to scan the skin in a number of sections, therefore reducing the constraint on the size of the measurement from 8 metres to 3 metres the database revealed that a photogrammetry camera combined with a white light target projector would potentially be able to carry out this operation. It might also be possible to use multiple projectors to extend the coverage. It is important to note however that the uncertainty of this system is highly dependent on the quality of the dots projected which is in turn dependent on the properties of the surface.

Removing the constraint on the time of the operation it was found that a Laser Tracker would be able to meet all of the other requirements with a total measurement time of approximately 4 hours. In practice it might be difficult to locate the correct positions to be measured but this remains an option worth considering since the use of a laser tracker with its associated retroreflector would remove any potential problems caused by the poor optical properties of carbon fibre.

There was also a possibility of reducing the variability in robotic machining operations so that the requirement for the surface characterization could be relaxed to an expanded uncertainty of less than $\pm 0.2 \mathrm{~mm}$. If this were the case then Laser Radar would be able to carry out the operation within all of the constraints.

The three possible instruments which could potentially be used are photogrammetry with active white light target projection, laser tracker or laser radar. There are potential issues and compromises involved in each. The use of instrument selection software facilitated an objective analysis of the optimum instrumentation. This is contrast to the typical selection process used in industry where the first step is to contact instrument vendors and ask them what they are able to provide that meets the specification. The selection process is then one of choosing between tenders rather than objectively selecting an optimized process.

\section{CONCLUSION}

A comprehensive measurement planning methodology has been specified. Existing process models have been combined with newly created process models and a prototype instrument selection and measurability analysis application has been created. The modelling of the process of instrument selection is anticipated to produce significant cost savings both by reducing the time spent in the selection process its-self and by providing a framework for objective analysis which is necessary to counter the tendency of metrology instrument manufacturers to oversell the complexity of their solutions.

Ultimately the greatest cost savings for industry could be realized by embedding considerations of measurability at the early stage of product design so that metrology optimisation is built into the early design stage. Currently this is generally not done resulting in products that are costly to verify.

The current prototype application uses generic database filters to specify the measurement process requirements which may be confusing for some users. A more refined solution would be to input the entire user input using a dialogue box interface such as the one illustrated in Figure 4. Although it appears from the image that this work has been completed in reality the creation of the graphical user interface is relatively strait forward. The challenges in implementing this approach will include incorporating the database queries required to filter and sort the instrument database. Additionally maintaining the flexibility of a filtering and sorting will be a particular challenge. 


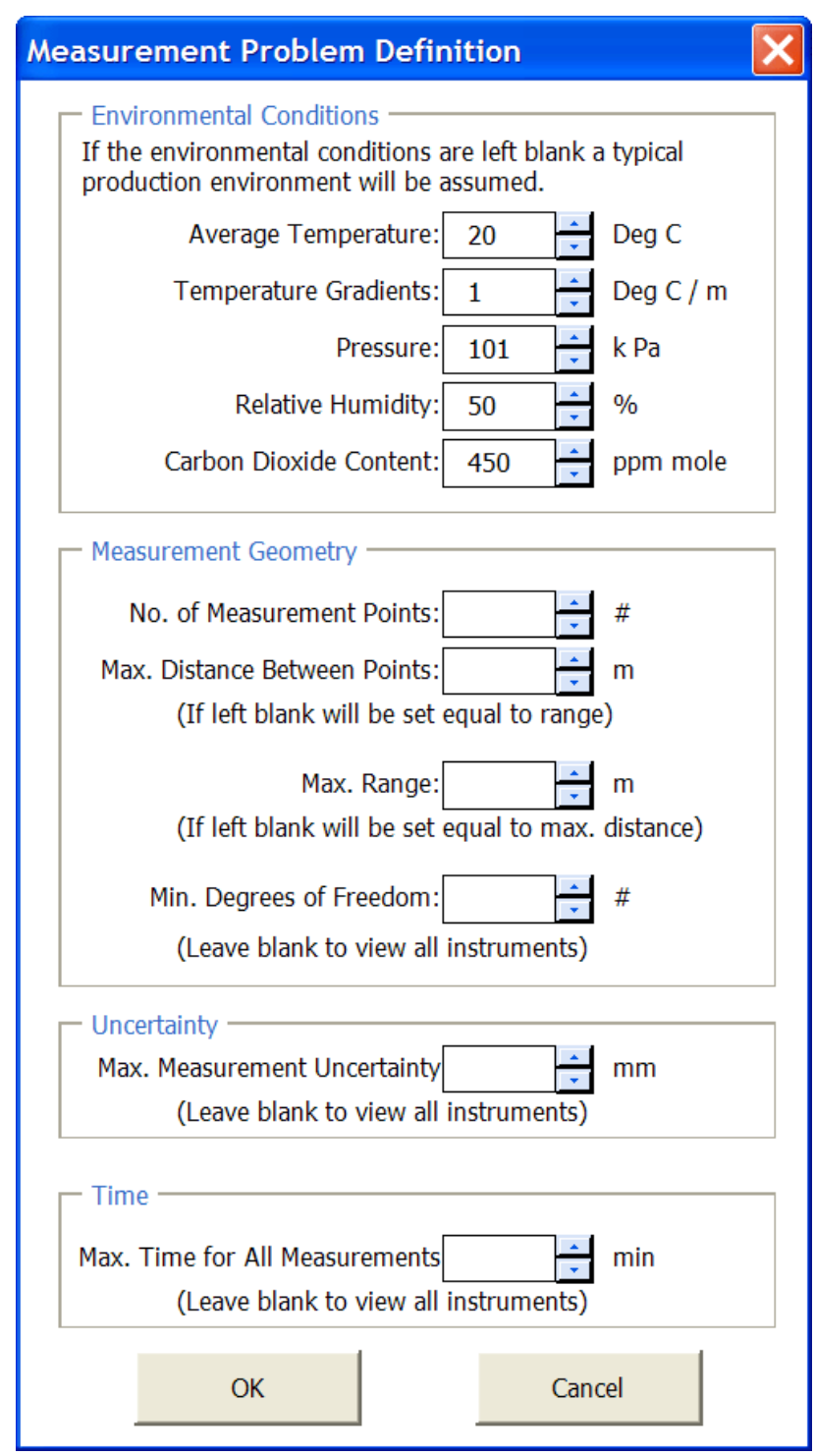

Figure 4: Example of User Input Form

The aspects of the process which cannot be easily modelled within this database approach are the aspects where process models are least developed. Specifically the modelling of access and visibility will require significant work to develop models within a threedimensional environment. Once these models are developed it will be possible to integrate them into the database orientated application.

Integration with a measurement network simulation algorithm, whether based on a Monte Carlo approach [27], on Finite Difference [31] or some other method, could be used to quantify the performance of actual instruments in the particular measurement process. Such networks could be optimized based on constraints such as line of sight or the physical location of the instrument.

In summary there are three phases of development required to fully realise the potential of this software. The first phase is to streamline the user interface and rationalize the process models used while maintaining essentially the same functionality as the prototype system. The second stage of development, which is likely to prove considerably more challenging, is to develop new process models for access and visibility. This second stage will require integration with a three-dimensional digital environment such as CATIA/DELMIA. Additional tasks, which may be completed at either of these stages, are the integration of process models describing the combined uncertainty for distributed measurement networks and more detailed cost models.

The third and final stage in the development of the measurement planning software is to incorporate optimization algorithms. This could allow networks of instruments to be automatically created and positioned within a production tooling environment. Constraints to this optimization would include the user specified inputs and the physical access and visibility constraints defined by the three-dimensional solid model. Optimization of multiple requirements such as uncertainty and cost minimization may be carried out using the measurability index as an objective function.

Use of the system to solve real industrial problems should occur at each stage in the development to ensure the application remains relevant to the end users. It is important to note that use of an automated system such as the one described is only the first step in ensuring the metrology process is fit for purpose and it is not a substitute for subsequent accreditation of the resulting measurement process, to provide final confidence to a manufacturer that the whole system is fit for purpose, for example as specified in the ISO17025 standard. However, this automated selection of instrumentation is a necessary part of an eventual ISO17025 process especially in very complex large scale measurement enabled environments.

\section{APPENDIX}

\subsection{Example Database}

Table 2 and Table 3 detail the structure of the database which forms the basis of the prototype measurement planning tool. It is worth noting that a UML class diagram could be used to represent some of this information. It is understood however that UML is not always the most appropriate way to represent information contained in software [32]. A UML class diagram could represent each table as a class and each field as a property. This would allow the data types of the properties to be specified but would not allow more detailed validation rules and explanation to be included. The table based specification is a more suitable way to represent this data. 
Table 2 : Field Descriptions for Instrument Database Process Specification Table

\begin{tabular}{|c|c|c|c|c|}
\hline Field Type & Field Name & Units & $\begin{array}{l}\text { Validation } \\
\text { Rules }\end{array}$ & Details \\
\hline Property 1 & Range & m & $\begin{array}{l}\text { +ve Real } \\
\text { Number }\end{array}$ & $\begin{array}{l}\text { Maximum range from instrument to measurement } \\
\text { points }\end{array}$ \\
\hline Property 2 & Size & M & $\begin{array}{l}\text { +ve Real } \\
\text { Number }\end{array}$ & Maximum length between measurement points \\
\hline Property 3 & $\begin{array}{l}\text { Concurrent } \\
\text { Points }\left(N_{a}\right)\end{array}$ & - & $\begin{array}{l}\text { +ve Natural } \\
\text { Number }\end{array}$ & $\begin{array}{l}\text { Number of points to be measured with part and } \\
\text { instrument in one location }\end{array}$ \\
\hline Property 4 & $\begin{array}{l}\text { Temperature } \\
\text { Gradients }\end{array}$ & $\stackrel{\circ}{\circ} / \mathrm{m}$ & $\begin{array}{l}\text { +ve Real } \\
\text { Number }\end{array}$ & Typical Temperature Gradients in working volume \\
\hline Property 5 & Tolerance & m & $\begin{array}{l}\text { +ve Real } \\
\text { Number }\end{array}$ & $\begin{array}{l}\text { Tolerance of dimension to be measured } \\
\qquad(+/- \text { value })\end{array}$ \\
\hline
\end{tabular}

Table 3: Field Descriptions for Instrument Database - Instrument Performance Characteristics (Continued)

\begin{tabular}{|c|c|c|c|c|}
\hline Field Type & Field Name & Units & Validation Rules & Details \\
\hline Class 1 & $\begin{array}{l}\text { Instrument } \\
\text { Type }\end{array}$ & - & Text & Generic type of instrument \\
\hline Class 2 & Instrument & - & Text & Manufacturer, Model \\
\hline Class 3 & Configuration & - & Text & Description of instrument or network configuration \\
\hline Property 1 & $\begin{array}{l}\text { Instrument } \\
\text { Uncertainty }\end{array}$ & $\mu \mathrm{m}$ & $\begin{array}{l}\text { +ve Real } \\
\text { Number }\end{array}$ & $\begin{array}{l}\text { Measurement Uncertainty for instrument in } \\
\text { specified configuration. Either a constant value or } \\
\text { some function of the Range and Size defined in the } \\
\text { Process Specification Table. }\end{array}$ \\
\hline Property 2 & Optical? & & $\begin{array}{c}\text { Angular / Range } \\
\text { / No }\end{array}$ & $\begin{array}{l}\text { If the instrument is optical then enter whether the } \\
\text { accuracy is dominated by angular or range errors, } \\
\text { if it is not optical then enter 'No'. }\end{array}$ \\
\hline Property 3 & $\begin{array}{l}\text { Optical } \\
\text { Errors }\end{array}$ & $\mu \mathrm{m}$ & $\begin{array}{l}\text { +ve Real } \\
\text { Number }\end{array}$ & $\begin{array}{l}\text { Calculated from the range and environmental } \\
\text { conditions IF it is an optical instrument using the } \\
\text { process models ELSE is zero. }\end{array}$ \\
\hline Property 4 & $\begin{array}{l}\text { Measurement } \\
\text { Time } \\
\left(t_{m}\right)\end{array}$ & $\mathbf{s}$ & $\begin{array}{l}\text { +ve Real } \\
\text { Number }\end{array}$ & $\begin{array}{l}\text { Typical time to take a single measurement. For } \\
\text { example a Laser Tracker requires time to average } \\
\text { readings and for the operator to move the SMR, } \\
\text { sequential multilateration with } 4 \text { tracker positions } \\
\text { would require } 4 x \text { as long. For a Laser Scanner this } \\
\text { will simply be } 1 / \text { measurement frequency. }\end{array}$ \\
\hline Property 5 & $\begin{array}{l}\text { Concurrency } \\
\left(N_{l}\right)\end{array}$ & - & $\begin{array}{l}\text { +ve Natural } \\
\text { Number }\end{array}$ & $\begin{array}{l}\text { The number of points the instrument is able to } \\
\text { measure simultaneously. For sequential } \\
\text { instruments the value is one, for multi-sensor then } \\
\text { it is the number of supported sensors and for } \\
\text { photographic instruments it is the number of } \\
\text { targets which can be imaged simultaneously. }\end{array}$ \\
\hline Property 6 & $\begin{array}{l}\text { Positioning } \\
\text { Time } \\
\left(t_{P}\right)\end{array}$ & $\mathbf{s}$ & $\begin{array}{l}\text { +ve Real } \\
\text { Number }\end{array}$ & $\begin{array}{l}\text { The setup time required each time the points being } \\
\text { measured are moved, for example when using } \\
\text { sequential multi-lateration this will be the total time } \\
\text { for all the station moves, if scanning patches of a } \\
\text { part it is the repositioning time between patches, } \\
\text { for some systems it will be zero. }\end{array}$ \\
\hline Property 7 & $\begin{array}{c}\text { Total } \\
\text { Uncertainty }\end{array}$ & $\mu \mathrm{m}$ & $\begin{array}{l}\text { +ve Real } \\
\text { Number }\end{array}$ & $\begin{array}{l}\text { Calculated by adding Instrument Uncertainty and } \\
\text { the Optical Errors }\end{array}$ \\
\hline Property 8 & Scale & m & $\begin{array}{l}\text { +ve Real } \\
\text { Number }\end{array}$ & $\begin{array}{l}\text { The longest length in the volumetric coverage, } \\
\text { used for simple filtering. More detailed } \\
\text { consideration of the actual form of the coverage } \\
\text { will be required to determine if the instrument is } \\
\text { able to make the measurement. }\end{array}$ \\
\hline
\end{tabular}


Table 3: Field Descriptions for Instrument Database - Instrument Performance Characteristics (Continued)

\begin{tabular}{|c|c|c|c|c|}
\hline Field Type & Field Name & Units & Validation Rules & Details \\
\hline Property 9 & $\begin{array}{l}\text { Fixed } \\
\text { Targets? }\end{array}$ & - & Yes/No & $\begin{array}{c}\text { Are fixed targets required or can measurements be } \\
\text { taken at arbitrary points on a surface? }\end{array}$ \\
\hline Property 10 & $\begin{array}{l}\text { Composite } \\
\text { Time }\left(T_{P}\right)\end{array}$ & $\mathbf{s}$ & $\begin{array}{l}\text { +ve Real } \\
\text { Number }\end{array}$ & Calculated from Equation ( 3 ) \\
\hline Property 11 & $\begin{array}{l}\text { Measurement } \\
\text { Frequency }\end{array}$ & $\mathrm{Hz}$ & $\begin{array}{l}\text { +ve Real } \\
\text { Number }\end{array}$ & $\begin{array}{c}\text { The measurement frequency of the instrument; } \\
\text { important for averaging out environmental } \\
\text { disturbances }\end{array}$ \\
\hline Property 12 & DOF & - & Integer 1-6 & $\begin{array}{l}\text { Degrees of freedom; a 1D length or angle, a 2D flat } \\
\text { shape, a 3D point in space or 6DOF full position } \\
\text { and rotation data (4 and } 5 \text { DOF are also possible). }\end{array}$ \\
\hline Property 13 & $\begin{array}{l}\text { Centralized } \\
\text { or } \\
\text { Distributed }\end{array}$ & - & $\begin{array}{l}\text { Centralized / } \\
\text { Distributed }\end{array}$ & $\begin{array}{l}\text { Are measurements taken from a single centralized } \\
\text { instrument or a distributed network? }\end{array}$ \\
\hline Property 14 & Part Interface & - & $\begin{array}{l}\text { Contact / Non- } \\
\text { contact }\end{array}$ & $\begin{array}{l}\text { Are measurement taken through physical contact } \\
\text { such as a CMM probe or SMR, or non-contact such } \\
\text { as a laser scanner or non-contact CMM probe }\end{array}$ \\
\hline Property 15 & SA Interface & - & Yes/No & $\begin{array}{c}\text { Can Spatial Analyzer be used to operate the } \\
\text { instrument? }\end{array}$ \\
\hline Property 16 & $\begin{array}{c}\text { SA } \\
\text { Simulation }\end{array}$ & - & Yes/No & $\begin{array}{l}\text { Can Spatial Analyzer be used to simulate the } \\
\text { measurement uncertainty? }\end{array}$ \\
\hline Property 17 & Setup Time & minute & $\begin{array}{l}\text { +ve Real } \\
\text { Number }\end{array}$ & $\begin{array}{c}\text { The time required to make the instrument ready for } \\
\text { measurement after transportation. }\end{array}$ \\
\hline Property 18 & $\begin{array}{l}\text { Packed } \\
\text { Volume }\end{array}$ & $\mathrm{m}^{3}$ & $\begin{array}{l}\text { +ve Real } \\
\text { Number }\end{array}$ & $\begin{array}{l}\text { Volume of the instrument when packed for } \\
\text { transport. }\end{array}$ \\
\hline Field Type & Field Name & Units & $\begin{array}{l}\text { Allowable } \\
\text { Values }\end{array}$ & Details \\
\hline Property 19 & Min Temp. & $\stackrel{\circ}{\circ}$ & $\begin{array}{l}\text { +ve Real } \\
\text { Number }\end{array}$ & $\begin{array}{l}\text { The minimum temperature the instrument is } \\
\text { certified to operate at. }\end{array}$ \\
\hline Property 20 & Max Temp. & $\stackrel{\circ}{ }{ }^{-}$ & $\begin{array}{l}\text { +ve Real } \\
\text { Number }\end{array}$ & $\begin{array}{l}\text { The maximum temperature the instrument is } \\
\text { certified to operate at. }\end{array}$ \\
\hline Property 21 & Min Altitude & m & $\begin{array}{l}\text { +ve Real } \\
\text { Number }\end{array}$ & $\begin{array}{c}\text { The minimum altitude the instrument is certified to } \\
\text { operate at. }\end{array}$ \\
\hline Property 22 & Max Altitude & m & $\begin{array}{l}\text { +ve Real } \\
\text { Number }\end{array}$ & $\begin{array}{c}\text { The maximum altitude the instrument is certified to } \\
\text { operate at. }\end{array}$ \\
\hline Property 23 & Min Humidity & $\%$ & $\begin{array}{l}\text { +ve Real } \\
\text { Number }\end{array}$ & $\begin{array}{l}\text { The minimum humidity the instrument is certified } \\
\text { to operate at. }\end{array}$ \\
\hline Property 24 & Max Humidity & $\%$ & $\begin{array}{l}\text { +ve Real } \\
\text { Number }\end{array}$ & $\begin{array}{l}\text { The maximum humidity the instrument is certified } \\
\text { to operate at. }\end{array}$ \\
\hline Property 25 & $\begin{array}{l}\text { Instrument } \\
\text { Cost }\end{array}$ & $\mathcal{E}$ & $\begin{array}{l}\text { +ve Real } \\
\text { Number }\end{array}$ & Cost of instrument or instruments for configuration \\
\hline Property 26 & $\begin{array}{l}\text { Information } \\
\text { Transfer }\end{array}$ & - & Text & $\begin{array}{l}\text { How information is propagated from measurement } \\
\text { points to the instrument datum. This could be by a } \\
\text { physical gantry or flexible arm, a single line of } \\
\text { sight, multiple lines of sight, ultrasonic, x-ray etc } \\
\text { This will require some descriptive explanation and } \\
\text { consideration of the task at hand. }\end{array}$ \\
\hline Property 27 & $\begin{array}{l}\text { Volumetric } \\
\text { coverage }\end{array}$ & - & Text & $\begin{array}{l}\text { Details of form and dimensions of volumetric } \\
\text { coverage }\end{array}$ \\
\hline Property 28 & Notes & - & Text & $\begin{array}{l}\text { Details of accuracy, sources of data and } \\
\text { assumptions made. }\end{array}$ \\
\hline Property 29 & TRL & - & Integer 1-4 & The Technology Readiness Level \\
\hline Property 30 & cost!!! & $\mathcal{E}$ & Currency & $\begin{array}{c}\text { The total cost calculated for the measurement } \\
\text { operation }\end{array}$ \\
\hline
\end{tabular}




\subsection{Notation}

\begin{tabular}{|c|c|c|}
\hline Variable & Units & Description \\
\hline $\boldsymbol{A}$ & - & $\begin{array}{l}\text { Constant used in calculation of } \\
\text { measurement uncertainty }\end{array}$ \\
\hline$B$ & - & $\begin{array}{l}\text { Constant used in calculation of } \\
\text { measurement uncertainty }\end{array}$ \\
\hline$C$ & - & $\begin{array}{l}\text { Constant used in calculation of } \\
\text { measurement uncertainty }\end{array}$ \\
\hline$C$ & $£$ & Cost of part \\
\hline$C_{C i}^{\prime}$ & - & $\begin{array}{c}\text { Dimensionless cost index for ith } \\
\text { instrument in database }\end{array}$ \\
\hline$C_{m i}^{\prime}$ & - & $\begin{array}{l}\text { Dimensionless measurement } \\
\text { capability index for ith } \\
\text { instrument in database }\end{array}$ \\
\hline$C_{r i}^{\prime}$ & - & $\begin{array}{l}\text { Dimensionless technology } \\
\text { readiness index for ith } \\
\text { instrument in database }\end{array}$ \\
\hline$C_{c}$ & $£$ & $\begin{array}{l}\text { Cost of carrying out a } \\
\text { measurement }\end{array}$ \\
\hline$C_{d}$ & $£$ & $\begin{array}{l}\text { Deployment cost of setting up } \\
\text { an instrument for measurement }\end{array}$ \\
\hline$C_{m}$ & - & Measurement capability index \\
\hline$C_{o}$ & $£$ & $\begin{array}{c}\text { Operating cost of employing an } \\
\text { instrument to carry out a } \\
\text { measurement }\end{array}$ \\
\hline$C R_{d}$ & E/hour & $\begin{array}{l}\text { Cost per unit time related to } \\
\text { instrument deployment }\end{array}$ \\
\hline$C R_{O}$ & E/hour & $\begin{array}{l}\text { Cost per unit time related to } \\
\text { instrument operation }\end{array}$ \\
\hline$c_{u}$ & $\mathfrak{E}$ & $\begin{array}{c}\text { Utilization cost of employing an } \\
\text { instrument to carry out a } \\
\text { measurement }\end{array}$ \\
\hline$D$ & - & $\begin{array}{l}\text { Constant used in calculation of } \\
\text { measurement uncertainty }\end{array}$ \\
\hline$I_{i}$ & - & $\begin{array}{l}\text { Overall measurement capability } \\
\text { index }\end{array}$ \\
\hline$M$ & $\sigma$ & Manufacturing uncertainty \\
\hline$N_{a}$ & \# & $\begin{array}{c}\text { Number of point to be measured } \\
\text { in a single position }\end{array}$ \\
\hline$N_{I}$ & $\#$ & $\begin{array}{c}\text { Number of points an instrument } \\
\text { is capable of measuring } \\
\text { concurrently }\end{array}$ \\
\hline
\end{tabular}

\begin{tabular}{|c|c|c|}
\hline Variable & Units & Description \\
\hline$r$ & m & Range \\
\hline$T$ & \% & $\begin{array}{c}\text { Rate of parts rejected which are } \\
\text { within tolerance due to } \\
\text { measurement uncertainty }\end{array}$ \\
\hline$T_{d}$ & hour & $\begin{array}{c}\text { Deployment time required to set- } \\
\text { up instrument }\end{array}$ \\
\hline$T_{I}$ & hour & Expering measured
\end{tabular}




\section{REFERENCES}

1 Womack, J.P., Jones, D.T. and Roos, D. The Machine that Changed the World. (Rawson Associates New York, 1990).

2 Fabricius, F. Seven step procedure for design for manufacture. World Class Design to Manufacture, 1994, 1(2), 23-30.

3 Maropoulos, P.G., Yao, Z., Bradley, H.D. and Paramor, K.Y.G. Integrated design and planning environment for welding Part 1: product modelling. Journal of Materials Processing Technology, 2000, 107(1-3), 3-8.

4 Maropoulos, P.G., Bramall, D.G. and McKay, K.R. Assessing the manufacturability of early product designs using aggregate process models. Proceedings of the Institution of Mechanical Engineers, Part B: Journal of Engineering Manufacture, 2003, 217(9), 1203-1214.

5 Cai, B., Guo, Y., Jamshidi, J. and Maropoulos, P.G. Measurability Analysis Of Large Volume Metrology Process Model For Early Design. 5th International Conference on Digital Enterprise TechnologyNantes, France, 2008).

6 ASME. Performance Evaluation of Laser-Based Spherical Coordinate Measurement Systems. B89.4.192006).

7 BSI. General Metrology - Part 3: Guide to the expression of uncertainty in measurement (GUM). PD 6461-31995).

8 Muelaner, J.E. and Maropoulos, P.G. Large Scale Metrology in Aerospace Assembly. 5th International Conference on Digital Enterprise TechnologyNantes, France, 2008).

9 BSI. Geometrical Product Specifications (GPS) Inspection by measurement of workpieces and measuring equipment - Part 1: Decision rules for proving conformance or non-conformance with specifications. BS EN ISO 142531:19991999).

10 Lau, K., Hocken, R. and Haight, W. Automatic Laser Tracking Interferometer System for Robot Metrology. pp. 100102Interlaken, Switz, 1985).

11 Estler, W.T., Edmundson, K.L., Peggs, G.N. and Parker, D.H. Large-scale metrology - An update. CIRP Annals Manufacturing Technology, 2002, 51(2), 587-609.

12 Department of Defence. Defence Acquisition Guidebook. (Department of Defence, USA, 2006).

13 Mankins, J.C. Technology Readiness Levels: A White Paper. (NASA, 1995).

14 Maisano, D.A., Jamshidi, J., Franceschini, F., Maropoulos, P.G., Mastrogiacomo, L., Mileham, A.R. and Owen, G.W. A comparison of two distributed large volume measuring systems: MScMS and iGPS. 2008).

15 Maisano, D.A., Jamshidi, J., Franceschini, F., Maropoulos, P.G., Mastrogiacomo, L., Mileham, A.R. and Owen, G.W. A comparison of two distributed large-volume measurement systems: the mobile spatial co-ordinate measuring system and the indoor global positioning system. Proc. IMechE Part B: J. Engineering Manufacture, 2009, 223, 511-521.

16 Huntley, J.M. Optical shape measurement technology: past, present and future. pp. 162-173 (Society of Photo-Optical Instrumentation Engineers, Bellingham, WA, USA, Glasgow, UK, 2000).

17 Mermelstein, M.S., Feldkhun, D.L. and Shirley, L.G. Video-rate surface profiling with acousto-optic accordion fringe interferometry. Optical Engineering, 2000, 39(1), 106-113.

18 New River Kinematics.2007. SpatialAnalyzer. v

19 Peggs, G.N., Maropoulos, P.G., Hughes, E.B., Forbes, A.B., Robson, S., Ziebart, M. and Muralikrishnan, B. Recent developments in large-scale dimensional metrology. Proc.
IMechE Part B: J. Engineering Manufacture, 2009, 223, In Print.

20 Stone, J.A. and Zimmerman, J.H. Index of Refraction of Air. p. Calculate wavelength in ambient conditions using Ciddor Equation (NIST, 2000).

21 Ciddor, P.E. Refractive index of air: new equations for the visible and near infrared. Appl. Optics, 1996, 35, 1566-1573.

22 Brown, D.C. Close-Range Camera Calibration. Photogrammetric Engineering, 1971, 855-866.

23 Geodetic Systems. Inca 3 - Picture Perfect Measurements. 2005).

24 Muelaner, J.E., Wang, Z., Jamshidi, J., Maropoulos, P.G., Mileham, A.R., Hughes, E.B. and Forbes, A.B. iGPS An Initial Assessment Of Technical And Deployment Capability. 3rd International Conference on Manufacturing Engineering, pp. 805-810Kassandra-Chalkidiki, Greece, 2008).

25 Triggs, B., Mclauchlan, P., Hartley, R. and Fitzgibbon, A. Bundle Adjustment - A Modern Synthesis. Vision Algorithms: Theory and Practice, International Workshop on Vision AlgorithmsCorfu, Greece, 1999).

26 Cox, M.G., Forbes, A.B., Fossati, P.M., Harris, P.M. and Smith, I.M. Techniques for the efficient solution of large scale calibration problems. CMSC2003).

27 Calkins, J.M. Quantifying Coordinate Uncertainty Fields in Coupled Spatial Measurement Systems Mechanical Engineering, p. 226 (Virginia Polytechnic Institute and State University, Blacksburg, 2002).

28 Wikipedia. Depreciation: Activity depreciation. (Wikipedia, 2008).

29 Cuypers, W., Gestel, N.V., Voet, A., Kruth, J.P., Mingneau, J. and Bleys, P. Optical measurement techniques for mobile and large-scale dimensional metrology. Opt Laser Eng, 2008.

30 Department of Defence. Calibration Systems Requirements. MIL-STD-45662A1988).

31 Boudjemaa, R., Cox, M.G., Forbes, A.B. and Harris, P.M. Automatic Differentiation Techniques and their Application in Metrology. Report to the National Measurement Directorate, Department of Trade and Industry

From the Software Support for Metrology Programme (NPL, 2003).

32 Fowler, M. UML Distilled: A Brief Guide to the Standard Object Modeling Language. (Addison-Wesley, Boston, 2004). 